Jurnal Ilmu Budaya, Vol. 17, No. 1 Agustus Tahun 2020

\title{
EKOSOFI CANGKIR KERA DALAM CERITA RAKYAT "BANGLAS ANTARA RINTIS” KARYA HANG KAFRAWI DKK.
}

\author{
Mohd. Fauzi \\ Universitas Lancang Kuning \\ Email: mohd.fauzi_007@yahoo.co.id
}

\begin{abstract}
The research attempted to describe the ecosophy of "Cangkir Kera" in Riau Malay Folklore "Banglas Antara Rintis" written by Hang Kafrawi. The kind of research is library research and the method used was descriptive-qualitative. The data was collected by using simak method. The data analysis applies agih method with the deletion technique and the substitution technique. The data used was written language related to ecolinguistic in Banglas Antara Rintis written by Hang Kafrawi, et al. The result of the research shows that Allah SWT has given Malay the environment with various types of plants. One unique plant is "Cangkir Kera" which can be used as a medium of medicine for anyone who coughs. The old Malays use pure water in a "Cangkir Kera" to treat coughing and other kinds of disease. This way is a form of local Malay wisdom in utilizing their environment by always expecting help from Allah SWT.
\end{abstract}

Keywords: Ecosophy, Cangkir Kera, traditional medicine

\section{Pendahuluan}

Cerita rakyat setidaknya memiliki lima fungsi bagi pembacanya yakni fungsi rekreatif (hiburan), fungsi didaktif (pendidikan), estetis (keindahan), moralitas (pendidikan moral) dan religius (pendidikan agama).

Cerita rakyat mengusung kearifan lokal yang tidak ternilai harganya, termasuklah cerita rakyat Melayu Riau.
Banyak karya sastra Melayu yang mengangkat isu-isu sosial kemasyarakatan dan isu-isu lingkungan. Kandungan karya sastra yang bersifat multi dimensional ini menjadikan karya sastra Melayu selalu vivid (hidup) melintasi berbagai zaman.

Salah satu karya sastra yang mengangkat isu sosial dan lingkungan adalah cerita "Banglas Antara Rintis" 
Jurnal Ilmu Budaya, Vol. 17, No. 1 Agustus Tahun 2020

karya Hang Kafrawi, dkk. Cerita ini berasal dari Selat Panjang, Kabupaten Kepulauan Meranti. Menariknya, penulis mengangkat perubatan tradisional Melayu melalui cangkir kera yang merupakan kearifan lokal orang Melayu.

Dari deskripsi di atas, maka karya sastra Melayu harus dipertahankan dengan cara dikaji, disosialisasikan dan diajarkan dari generasi ke generasi agar nilai-nilai yang terkandung di dalamnya dapat dinikmati masyarakat dan tidak terancam punah. Saat ini banyak karya sastra bernilai tinggi yang mengangkat isu-isu sosial dan lingkungan sebagai salah satu upaya penyelamatan kearifan lokal.

Jika kajian dan sosialisasi dalam rangka pemertahanan tidak dilakukan dari sekarang, maka dikuatirkan karya-karya tersebut terbiar begitu saja dan lamakelamaan akan punah.

Penelitian ini adalah penelitian ekolinguistik kritis, artinya menganalisis fenomena kebahasaan yang ada kaitannya dengan lingkungan. Alasan perlunya upaya penyelamatan bahasa yang menjadi teraju pengusung persoalan sosial masyarakat karena "banyak bahasa daerah di belahan dunia ini termasuk Indonesia berada di ambang kritis, semakin sulit untuk untuk bertahan hidup, berfungsi, dan terwariskan secara utuh. Banyak nilai kearifan dan pengetahuan asli lokal yang tergusur dan punah. Belum lagi, dengan ancaman hegemoni dan dominasi beberapa bahasa internasional, regional dan nasional, semakin mendesak bahasa-bahasa minoritas" (Sinar, 2010: 70).

Penelitian yang sudah pernah dilakukan terkait cerita rakyat Melayu Riau dalam lima tahun terakhir antara lain; Kusumawardani, dkk. (2020) "Reduplikasi Dalam Cerita Rakyat Melayu Riau"; Siregar, K.A.J., dkk. (2020) "Kajian Struktur, Fungsi, Dan Nilai Moral Cerita Rakyat Sebagai Bahan Pembelajaran Apresiasi Sastra"; Hijiriah (2017) "Kearifan Lokal Cerita Rakyat Masyarakat Kabupaten Karimun Kepulauan Riau”; Sabakti (2016) "Cerita Rakyat Indragiri Hulu: Analisis Strukturalisme Levi-Strauss". 
Jurnal Ilmu Budaya, Vol. 17, No. 1 Agustus Tahun 2020

Dari penelusuran literatur, kajiankajian relevan sebelumnya belum ada yang membahas Ekosofi cerita rakyat Melayu Riau. Nilai-nilai ekosofi menjadi sesuatu yang sangat penting karena akan mengungkap falsafah dan kearifan lokal Melayu Riau dengan lebih mendalam untuk kemaslahatan masyarakat banyak.

Ekosofi adalah sebuah filosofi ekologis, yaitu seperangkat prinsip dan asumsi normatif tentang hubungan antar manusia, bentuk kehidupan lain dan lingkungan fisik. Analis menggunakan ekosofi mereka sendiri untuk menilai cerita yang mereka ungkapkan melalui analisis linguistik. (Stibbe, 2015: 15)

Ekosofi, menurut definisi, termasuk pertimbangan interaksi yang menopang kehidupan antara manusia, spesies lain dan lingkungan fisik. Namun, prinsip, norma, dan nilai-nilai tepat dari ekosofi adalah untuk menentukan analisis individu. Ekosofi bervariasi pada skala dari antroposentris (di mana fokusnya hanya pada kesejahteraan manusia), hingga ekosentris (di mana manusia dan spesies lain dianggap memiliki nilai intrinsik). Cerita dinilai destruktif jika mereka menentang ekosofi, dan kemudian ditentang (yaitu, dengan meningkatkan kesadaran bahasa kritis akan dampak potensial dari cerita). Di sisi lain, mereka dinilai menguntungkan jika mereka cocok dengan ekosofi di mana orang didorong untuk berpikir dan bertindak untuk menyelamatkan sifat yang menjadi sandaran kehidupan (Astawa, 2019).

Pola apraisal digunakan untuk pendeskripsian data. Sinar (2010) menyatakan bahwa teori Apraisal adalah konsep evaluasi untuk mengungkapkan penilaian penutur, baik tersirat maupun tersurat, terhadap pokok pembicaraan, lawan bicara, ataupun dunia yang mungkin berhubungan dengan parameter evaluatif, seperti sikap, pemosisian, yang meliputi di antaranya epistemik, reabilitas, evidensialitas, dan graduasi.

Berkaitan dengan ekosofi Stibbe dan pendapat Astawa di atas, penelitian ini bertujuan untuk menganalisis dan menjelaskan ekosofi cangkir kera yang menjadi media penyampai informasi penulis cerita. 
Jurnal Ilmu Budaya, Vol. 17, No. 1 Agustus Tahun 2020

Cangkir kera merupakan jenis tumbuhan yang banyak ditemukan di semak-semak belukar di daerah Riau, tetapi tidak semua orang tahu manfaat dari cangkir kera tersebut. Masyarakat sering menyia-nyiakan tumbuh-tumbuhan ini dengan membiarkannya mati dan ditebas dengan alasan mengganggu dan memuat semak lahan karet mereka.

\section{Metodologi Penelitian}

Jenis penelitian ini adalah deskriptif kualitatif. Penelitian deskriptif kualitatif merupakan penelitian yang bertujuan membuat deskripsi, membuat gambaran, lukisan secara sistematis, faktual dan akurat mengenai data, sifat-sifat serta hubungan fenomena-fenomena yang diteliti. Pemilihan jenis penelitian deskriptif di dalam penelitian bahasa, cenderung digunakan terutama dalam mengumpulkan data serta menggambarkan data secara ilmiah (Djajasudarma, 2006:9). Data adalah bahan jadi penelitian (Sudaryanto, 2016: 66). Data penelitian ini kata-kata, frasa dan kalimat-kalimat yang berkaitan dengan lingkungan (ekolinguistik) dalam cerita rakyat Banglas Antara Rintis karya Hang Kafrawi, dkk. Pengumpulan data menggunakan teknik catat (Sudaryanto, 2016: 33).

Penyajian hasil analisis data dalam penelitian ini dilakukan dengan menggunakan metode informal dan formal. Penyajian informal yaitu berupa rumusan dengan menggunakan kata-kata biasa, sedangkan penyajian formal adalah perumusan dengan tanda dan lambanglambang (Sudaryanto, 1993:145). Demikian juga menurut Mahsun (2005:123) bahwa metode informal merupakan perumusan dengan menggunakan terminologi yang bersifat teknis, dan metode formal merupakan perumusan dengan menggunakan tandatanda atau lambang-lambang.

Alasan digunakannya metode informal dan formal dalam penyajian hasil analisis karena penelitian ini bersifat deskriptif. Maksudnya pendeskripsian dari gejala atau keadaan yang terjadi pada data penelitian. Penggunaan kedua metode tersebut karena selain penyajian dilakukan dengan menggunakan kata-kata 
Jurnal Ilmu Budaya, Vol. 17, No. 1 Agustus Tahun 2020

biasa juga dengan menggunakan tanda dan lambang-lambang.

\section{Hasil dan Pembahasan}

\section{A. Ekosofi Cangkir Kera dalam Banglas Antara Rintis}

Cerita rakyat "Banglas Antara Rintis" yang ditulis Kafrawi, dkk mengandung ekosofi hubungan manusia dengan alam, hubungan manusia dengan manusia serta hubungan manusia dengan Tuhannya. Dalam cerita ini dikisahkan seorang pemuda yang pekerjaan sehariharinya mencari kayu di hutan. Pemuda ini bernama Banglas, dan dia adalah seorang yang jujur dan baik hati.

Ketika dia sedang mencari kayu tiba-tiba dia melihat fenomena yang menakjubkan. Dia menyaksikan kera-kera yang kehausan dan berjalan lunglai mencari cangkir kera untuk dijadikan pengobat haus dan sakit yang mereka derita.

Data (1) Banglas pun melihat beberapa kera sedang berjalan longlai menuju tumbuhan yang mirip cangkir. Tanpa ragu, kera-kera yang berjalan lemah itu mengambil dan memetik tumbuhan itu dan meminum air yang berada ditumbuhan seperti cangkir tersebut. Setelah memetik dan meminum air di tumbuhan tersebut, kera itu pergi. Beberapa saat, kerakera itu mampu memanjat, bergantungan dan meloncat dari dahan ke dahan di pohonpohon besar dengan segarbugar. Tidak terlihat kera-kera itu lemas tidak berdaya. (Banglas Antara Rintis, Hal: 79)

Menariknya, kera-kera yang sebelumnya lunglai dan kesakitan berubah dalam waktu yang tidak lama. Kera-kera tersebut tersebut menjadi segar bugar. Perlakuan kera ini merupakan ekosofi makhluk ciptaan Tuhan yang bisa ditiru oleh manusia. Banglas terkagum-kagum dengan cara kera mengobati sakitnya.

Data (2) Dari tempat persembunyian, Banglas memperhatikan semuanya. Dalam hati Banglas berkata, bahwa tentulah air tumbuhan yang diminum kerakera itu bisa menyembuhkan penyakit. "Tuhan Maha Besar menciptakan sesuatu bermanfaat untuk semua yang hidup”, ujar Banglas. Dengan keyakinan yang besar, Banglas pun mengambil beberapa 
Jurnal Ilmu Budaya, Vol. 17, No. 1 Agustus Tahun 2020

batang tumbuhan yang

berbentuk cangkir tersebut

untuk mengobati emaknya yang

sedang sakit. Setelah

memetiknya, dengan hati-hati

Banglas membawa pulang

tumbuh-tumbuhan tersebut

agar airnya tidak tumpah.

(Banglas Antara Rintis, 79)

Setelah mengamati tingkah laku

kera-kera tersebut, Banglas teringat akan ibunya yang sedang sakit batuk yang sudah lama dideritanya. Pengamatannya terhadap apa yang dikerjakan para kerakera itu menginspirasinya untuk mengobati ibunya dengan air dari dalam cangkir kera itu. Dari sini dapat dilihat dengan jelas bahwa Banglas sangat cerdas dalam melihat fenomena alam. Upaya Banglas melakukan pengamatan tersebut adalah bentuk apraisal positif (positive appraisal) karena belajar dari alam dan mempraktikkan dalam kehidupannya.

Tumbuhan cangkir kera atau kantong semar yang selama ini tidak dia hiraukan, kini memberikan harapan besar untuk menyembuhkan sakit batuk ibunya. Waktu itu belum ada dokter yang mengobati pasiennya dengan obat-obatan yang sudah bercampur zat kimia.
Masyarakat Melayu harus melakukan pengamatan terhadap alam sekitarnya untuk dijadikan obat. Kearifan lokal yang mereka miliki menyebabkan mereka mampu melewati berbagai bentuk rintangan hidup, salah satunya dalam hal perubatan.

Setelah Banglas sampai di rumah dengan penuh harap dan berdo'a kepada Allah, dia meminumkan air dalam cangkir kera tersebut kepada ibunya. Dalam waktu yang tidak lama ibunya sembuh dari batuk berat yang dideritanya.

Banglas juga mempraktekkan pengobatan dengan air murni dari cangkir kera kepada pendekar Antara yang terluka sangat parah akibat ditikam berulangulang oleh pendekar Tebing. Meskipun sudah banyak cara dilakukan untuk mengobati lukanya, tetapi pendekar Antara belum juga sembuh dari sakitnya.

Pendekar Antara adalah orang yang sombong dan congkak. Dia merasa dialah orang yang paling kuat dan tidak terkalahkan, tetapi akhirnya dia kalah dari pendekar Tebing. Benar jugalah kata pepatah, di atas langit masih ada langit. 
Jurnal Ilmu Budaya, Vol. 17, No. 1 Agustus Tahun 2020

Pendekar Antara juga sangat membenci

Banglas karena Rintis lebih mencintai

Banglas daripada dirinya, tetapi Banglas tidak pendendam. Dia merasa kasihan kepada pendekar Antara yang sudah menderita kesakitan dengan lukanya.

Perlakukan Banglas kepada pendekar Antara adalah bentuk apraisal positif (positive appraisal) yang tidak suka menyimpan dendam tetapi ikhlas menolong orang yang selalu meremehkannya.

Akhirnya Banglas meyakinkan pendekar Antara agar memberikannya kesempatan untuk mengobati lukanya. Pendekar Antara kemudian pasrah saja karena sudah terlalu banyak usaha yang telah dilakukannya. Ajaibnya, dalam waktu satu malam Banglas sudah dapat menyembuhkan pendekar Antara.

Data (3) Dengan membaca sedikit do'a, Banglas menuangkan air dari tumbuhan itu ke mulut Pendekar Antara, kemudian sisanya dituangkan di luka pendekar Antara. Setelah selesai melakukan pengobatan itu, Banglas dan Rintis meminta diri untuk balik ke rumah mereka. Perasaan lega mengalir di tubuh
Banglas. Ia telah mampu mengalahkan perasaan khawatirnya. (Banglas Antara Rintis, 84)

Cara pengobatan dari bahan-bahan lingkungan sekitar merupakan apraisal positif (positive appraisal) kepada alam dan memanfaatkan karunia Tuhan dengan sebaik-baiknya. Pengamatan secara mendalam terhadap fenomena sekitar untuk digunakan bagi kemaslahatan manusia. Apraisal positif lainnya ditunjukkan dalam Data (1) dan (2) adalah kereligiusan orang Melayu yang selalu bermohon kepada Allah SWT pada setiap tindakannya. Dalam melakukan pengobatan, Banglas selalu berserah diri kepada Allah SWT.

Kenyataan ini menunjukkan bahwa ketika ajaran Islam sudah sampai kepada orang Melayu, maka mereka berusaha menerapkannya dalam sendi-sendi kehidupan mereka.

Islam mengajarkan agar pemeluknya selalu mengamalkan ajaran agama dengan mengamalkan perintah dan menjauhkan larangan Allah SWT. Segala kebaikan yang dilakukan Banglas dan 
Jurnal Ilmu Budaya, Vol. 17, No. 1 Agustus Tahun 2020

Rintis berbuah kebaikan juga, menjadi obat tradisional untuk mengobati sebagaimana nasehat seorang kakek tua yang ditemuinya di jalan.

Data (4) "Jangan takut wahai cucucucuku. Kebaikan akan berbuah kebaikan," ujar orang tua tersebut. Orang tua itu pun kembali berucap. "Sebenarnya air dalam cangkir tumbuhan itu adalah air dari pohon rumbia yang bercampur dengan air hujan. Tersebab mengalami proses alami maka air itu bisa dijadikan penyembuh penyakit. Namun demikian, cucuku, tidak semua air yang ada dicangkir itu bisa dijadikan obat. Semuanya tergantung niat kita. Air itu hanya perantara keinginan Sang Maha Pencipta, Dia, Allah, yang menyembuhkan segala penyakit. Dengan izin Allah Swt, semuanya bisa terjadi," ujar orang tua itu. (Cerita Rakyat Riau, Banglas Antara Rintis: 83)

\section{Simpulan}

Ekosofi Cangkir kera ditunjukkan dengan kearifan Banglas dalam melihat dan mengamati fenomena alam di sekitarnya. Banglas belajar dari kera dalam mengobati sakitnya. Air murni dalam cangkir kera ternyata mampu 
Jurnal Ilmu Budaya, Vol. 17, No. 1 Agustus Tahun 2020

Hijiriyah, Siti. 2017. "Kajian Struktur, Fungsi, Dan Nilai Moral Cerita Rakyat Sebagai Bahan Pembelajaran Apresiasi Sastra". Riksa Bahasa. Vol. 3. No.1.

Kafrawi, Hang, dkk. 2015. Cerita Rakyat Riau. Pekanbaru: Dinas Pendidikan dan Kebudayaan Provinsi Riau.

Kurmalasari, T., dan Hamdan, A.R.. 2017. "Nilai-Nilai Karakter Building Dalam Gurindam Dua Belas Karya Raja Ali Haji”. Kiprah. Vol 3. No.1 (Uhamra).

Kusumawardani, W. Dkk. 2020. "Reduplikasi dalam Cerita Rakyat Melayu Riau”. Jurnal Online Mahasiswa FKIP. Universitas Riau. Vol 7. No. 1.

Mahsun. 2005. Metode Penelitian Bahasa: Tahapan Strategi, Metode, dan Tekniknya. Jakarta: Raja Grafindo Persada.

Nurliana. 2019. "Nilai Teologi Dalam Gurindam Dua Belas Raja Ali Haji”. El-Furqania: Jurnal Ushuluddin dan Ilmu-ilmu Keislaman. Vol 5 No. 9. Pamekasan.

Sabakti, S. Dkk. 2016 "Cerita Rakyat Indragiri Hulu: Analisis Strukturalisme Levi-Strauss". Balai Bahasa Riau.

Sinar, T. S. 2010. "Ungkapan Verbal Etnis Melayu dalam Pemeliharaan
Lingkungan." Disampaikan dalam Seminar Internasional SeminarLanguage, Literature, And Culture in Southheast Asia. Diselenggarakan oleh Prodi Linguistik USU dan Phuket Rajabhat University Thailand, Thailand 3-5 Juni 2010.

Sinar, Tengku Silvana. 2010. "Upaya Penelitian dalam Merawat Kearifan Lokal." Harian Analisa Medan, 7 Februari 2010.

Stibbe, Arran. 2015. Ecolinguistics: language, ecology, and the stories we live by. London and New York: Routledge.

Sudaryanto. 1992. Metode dan Aneka Teknik Analisis Bahasa. Yogyakarta: Duta Wacana University Press. 